\title{
Minority and Majority Influence in Freely Interacting Groups: Qualitative Versus Quantitative Differences
}

Christine M. Smith

Loyola University Chicago

Follow this and additional works at: https://ecommons.luc.edu/luc_theses

Part of the Psychology Commons

\section{Recommended Citation}

Smith, Christine M., "Minority and Majority Influence in Freely Interacting Groups: Qualitative Versus Quantitative Differences" (1993). Master's Theses. 3930.

https://ecommons.luc.edu/luc_theses/3930

This Thesis is brought to you for free and open access by the Theses and Dissertations at Loyola eCommons. It has been accepted for inclusion in Master's Theses by an authorized administrator of Loyola eCommons. For more information, please contact ecommons@luc.edu. (c) (i) $(9)$

This work is licensed under a Creative Commons Attribution-Noncommercial-No Derivative Works 3.0 License. Copyright @ 1993 Christine M. Smith 
Minority and Majority Influence in Freely Interacting Groups :

Qualitative Versus Quantitative Differences

by

Christine M. Smith

A Thesis Submitted to the Faculty of the Graduate School of Loyola University of Chicago in Partial Fulfillment of the Requirements for the Degree of Master of Arts

January

1993 
Copyright by Christine M. Smith, 1993

All Rights Reserved 


\section{ACKNOWLEDGEMENTS}

This project could not have been completed without the contributions and support of many individuals. I would like to thank my mentor and thesis director, Dr. R. Scott Tindale, for his enthusiasm, support, patience, and friendship. I am indebted to him for the intellectual stimulation he provided me during the course of this project.

I would like to thank my reader, Dr. Bernard Dugoni for his constructive comments and for his helpful advice regarding the analysis of my data.

I am greatful for all of the time Lyn VanSwol, Patti Lazar, and Kristin Bertholdt devoted to content analyzing my data.

I would like to express my gratitude to John Adamopoulos for his interest in my ideas, and for being a constant source of support, enthusiasm, and encouragement.

Finally, I would like to thank Marie Mackay, Linda Thomas, Jayne Edmundson, and Tracy Hess. Each, in their own way, helped me through many of the crises that arose during the course of this project. 
TABLE OF CONTENTS

COPYRIGHT PAGE $\ldots \ldots \ldots \ldots \ldots \ldots \ldots \ldots \ldots \ldots \ldots \ldots \ldots \ldots \ldots$

ACKNOWLEDGEMENTS ....................... i i

TABLE OF CONTENTS $\ldots \ldots \ldots \ldots \ldots \ldots \ldots \ldots \ldots \ldots \ldots \ldots \ldots$

LIST OF TABLES AND FIGURES ................. vi

I. INTRODUCTION $\ldots \ldots \ldots \ldots \ldots \ldots \ldots \ldots \ldots \ldots \ldots \ldots$

Models of Social Influence ........... 1

Empirical Test of Three Models ........ 5

Qualitative Differences in Majority and

Minority Influence ................ 7

Outline of the Present study and

Research Hypotheses ............... 15

II. METHOD .......................... 18

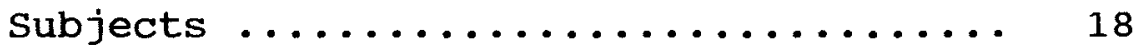

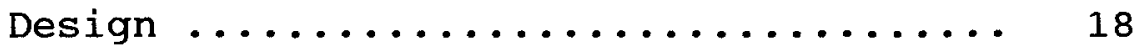

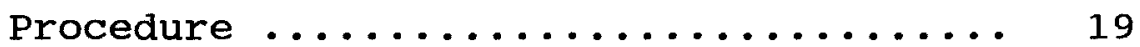

III. RESULTS ...................... 22

Attitude Change Due to Minority

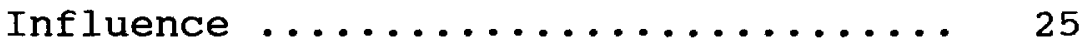

Attitude Change Due to Majority

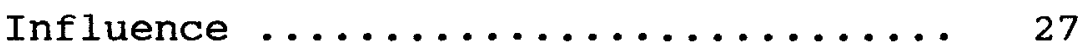

Minority Influence Thought Listing

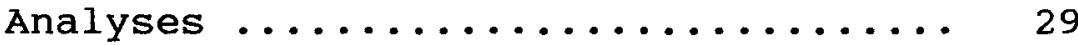


Cognitive Fluency Analyses : English

Language Issue ............. 30

Cognitive Flexibility: English

Language Issue ............. 33

Cognitive Fluency Analyses:

Legal Marriage Between Homosexuals

Issue $\ldots \ldots \ldots \ldots \ldots \ldots \ldots \ldots \ldots \ldots$

Cognitive Flexibility Analyses:

Legal Marriage Between Homosexuals

Issue $\ldots \ldots \ldots \ldots \ldots \ldots \ldots \ldots . \ldots \ldots$

IV. DISCUSSION ...................... 40

REFERENCES ............................. 52

APPENDIX A : English Attitude Scale ........... 57

APPENDIX B : English Thought Listing Form ....... 58

APPENDIX $C$ : Homosexuals Marrying Attitude

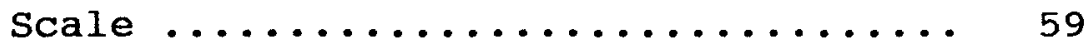

APPENDIX D : Homosexuals Marrying Thought Listing

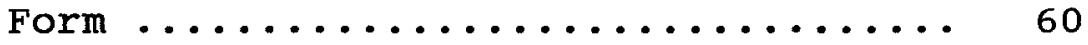

APPENDIX E : Debriefing Form ................ 61

CURRICULUM VITAE .......................... 62 


\section{LIST OF TABLES AND FIGURES}

Table

1 Mean Attitude Scores and Standard

Deviations at Pretest and Postest

for Minority and Majority Influence

Types ............................ 24

2 Mean Change Scores, Standard Deviations,

and cell size for Minority and

Majority Influence Types ............. 25

3 Analysis of Variance Source Table

for Change Scores: Unanimous Groups

and Groups Exposed to Minority

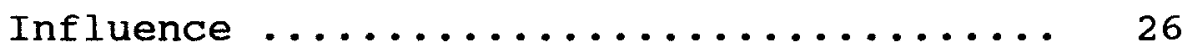

4 Number and Relative Frequency of Change

on Dichotomous Response for Majority

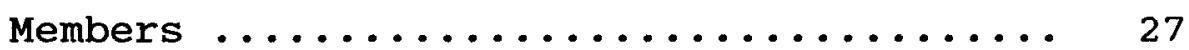

5 Analysis of Variance Source Table

for Change Scores: Minorities of one

and Minorities of Two ................. 28

6 Number and Relative Frequency of Change

on Dichotomous Response for Minority

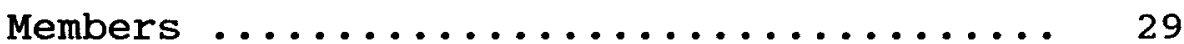


Analysis of Variance Source Table for Cognitive Fluency: Establishing English as the official Language of U.S. for Unanimous Groups and Groups Exposed to Minority Influence $\ldots \ldots \ldots \ldots \ldots \ldots$ Analysis of Variance Source Table: English Arguments for Unanimous Groups and Groups Exposed to Minority Influence $\ldots \ldots \ldots \ldots \ldots \ldots \ldots \ldots \ldots$

9 Analysis of Variance Source Table: English Counterarguments for Unanimous Groups and Groups exposed to Minority Influence $\ldots \ldots \ldots \ldots \ldots \ldots \ldots \ldots \ldots$

10 Analysis of Variance Source Table: English Flexibility for Unanimous Groups and Groups Exposed to Minority Influence $\ldots \ldots \ldots \ldots \ldots \ldots \ldots \ldots \ldots \ldots$

11 Analysis of Variance Source Table for Cognitive Fluency: Allowing Homosexuals to Marry Legally for Unanimous Groups and Groups Exposed to Minority Influence $\ldots \ldots \ldots \ldots \ldots \ldots \ldots \ldots \ldots \ldots \ldots$

12 Analysis of Variance Source Table for Arguments: Allowing Homosexuals to Marry Legally for Unanimous Groups and Groups Exposed to Minority 
Analysis of Variance Source Table for

Counterarguments: Allowing Homosexuals

to Marry Legally for Unanimous Groups

and Groups Exposed to Minority

Influence $\ldots \ldots \ldots \ldots \ldots \ldots \ldots \ldots \ldots \ldots$

14 Analysis of Variance Source Table for

Cognitive Flexibility: Allowing Homosexuals

to Marry Legally for Unanimous Groups and

Groups Exposed to Minority

Influence $\ldots \ldots \ldots \ldots \ldots \ldots \ldots \ldots \ldots \ldots$ 


\section{INTRODUCTION}

The identification of parameters predictive of social influence has long been an important goal of social psychology. Although the current literature still leaves many issues unresolved, a general rule has emerged from years of research: there is strength in numbers. The notion that faction size plays a critical role in social influence is central to three different models of social influence that are relevant to the present paper: social impact theory (Latané, 1981), other-total ratio (Mullen, 1983), and social influence model (Tanford \& Penrod, 1984). A detailed description of each model is beyond the scope of this proposal. However, social impact theory (SIT) will be discussed most thoroughly, and other-total ratio (OTR) and social influence models (SIM) will be contrasted to it. Models of Social Influence

Social impact theory (Latané, 1981) describes the process of social influence as a function involving three variables: strength, immediacy, and number of influence sources. These variables are multiplicatively related, as shown in Equation 1:

$$
I=f(S I N)
$$

where $I$ is influence or impact, $S$ is the strength of the influencing source, I is the immediacy of the source, and $\mathrm{N}$ 
is the number of influencing sources.

Strength refers to the source of influence, and includes factors such as economic and social status, age, and past incidents that involved the source exerting power over the target. Immediacy refers to the physical proximity of the source with respect to the target. Number refers to the number of influencing sources.

Although Latané considers all three factors (strength, immediacy, and number) equally important determinants of social influence, he focuses primarily on certain psychosocial laws, to be discussed presently. These laws deal solely with the Number parameter in Equation 1. The first psychosocial law, shown in Equation 2:

$$
\mathrm{I}=\mathbf{S N}^{\mathrm{t}}
$$

suggests that the amount of social impact (I) a target will experience is equal to a scaling constant (s) multiplied by the number of influencing sources (N) raised to some exponent $(t)$. The exponent will always be less than one, and the first few sources of influence will have a stronger impact upon the target than will the subsequent sources because impact is assumed to be related to a root of the number of influencing sources. Latané argues that just as a target presumably experiences a stronger and more powerful form of influence as the number of sources increases, a source's influential force will be divided amongst the 
targets as the number of targets increases. This is represented by the second psychosocial law, presented in Equation 3 :

$$
I=\mathbf{S N}^{-\mathbf{t}}
$$

This law implies that each individual target will be less influenced or persuaded by an influential message as the number of targets increases.

Most empirical tests of social impact theory have been directed towards the two psychosocial laws, rather than the complete model proposed by Latané. The diverse nature of dependent variables used in these studies suggests that these laws adequately describe social influence in many domains (e.g., tipping in restaurants, stage fright, worker productivity, classroom behavior, bystander intervention; see Latané, 1981, for a review). However, the value of the exponent $(t)$ is allowed to vary from study to study without theoretical explanation. The empirically derived value assigned to the exponent has led some theorists to argue that the psychosocial laws lack predictive power (Mullen, 1985). It is important to note, though, that the psychosocial laws are indeed predictive in that they predict the function form for patterns associated with influence produced by different sized factions (e.g., marginally decreasing impact). These patterns predicted by SIT have received considerable support and Latané has actually shown that data from past research, when reanalyzed, are in line 
with SIT (Gerard, Wilhelmy, \& Connolley, 1968; Latané \& Darley, 1970; 1975).

Self-attention theory (Carver \& Sheier, 1981) serves as the theoretical foundation for a second model of social influence, the other-total ratio (Mullen, 1983). This model proposes that faction size alone predicts social influence, and that for any individual the OTR is equal to the number of members in his/her opposing faction divided by the total number of group members. For example the OTR for a single individual facing a majority of 3 would be $3 / 4$. This model makes predictions quite similar to those of the psychosocial laws proposed by Latané in that it proposes that influence should increase in a marginally decreasing fashion as members are added to the opposing faction. This similarity in predictions, as well as the relative lack of empirical data in support of Latané's complete model of social influence, has led Mullen (1985) to argue that the other-total ratio is a more parsimonious conceptualization of social influence (but see Jackson, 1986, for a counterargument).

The third model of social influence (Tanford \& Penrod, 1984) differs from SIT in that it assumes individual differences in susceptibility to persuasion, and includes a parameter corresponding to such differences. Another parameter of SIM corresponds to the interactive nature of influence and allows for reciprocal influence effects. It 
should be noted, however, that Jackson (1987) extended SIT so that it is also capable of capturing the interactive nature of social influence. A parameter unique to SIM takes into account the consistency level of the sources. Lastly, SIM, like the previously discussed models, considers the number of influencing sources to be a critical predictor of influence.

Perhaps the largest difference between SIM and SIT, notwithstanding the additional parameters, is that SIM predicts that influence will reach an asymptote at $\mathrm{N}=4$ in most majority paradigms. SIT, on the other hand, predicts no limit or absolute amount of influence that may be experienced by a target, and, thus, the addition of sources will always result in an increase in influence. It is for this reason that the data from the Asch studies (1951; 1952; 1956) do not fit the pattern predicted by the SIT psychosocial laws. Asch found that the amount of influence did not systematically increase with the addition of sources, but, rather, leveled off after the third source of influence was added.

Empirical Test of the Three Models

Despite the differences in the predictions made by each of the three models discussed, Tindale, Davis, Vollrath, Nagao \& Hinsz (1990) have shown that there are almost no differences in the degree to which the models can fit the data collected in a model-testing investigation. Predictions 
made by SIT, SIM, and OTR, were tested in freely interacting groups. Tindale et al. (1990) also manipulated group composition (the number of minority and majority members), counterbalanced for the direction in which group members argued, and group size (ranging from three to six). Perhaps the most relevant finding with respect to this proposal is that shifts indicating that the minority faction was influential were found in only three out of twelve groups that had a minority faction (i.e., groups comprised of four majority members favoring a guilty verdict/two minority members favoring a not guilty verdict, three majority members favoring a guilty verdict/two minority members favoring a not guilty verdict, and two majority members favoring a guilty verdict/one minority member favoring a not guilty verdict). It is important to note here that group composition alone cannot account for these shifts because group composition was counterbalanced for argument direction, and three group compositions with the majority favoring not guilty did not show the slight shift toward the minority position. Most surprisingly, the majority factions of the remaining nine groups shifted in a direction opposite that of the minority faction and became more extreme. These results do not correspond to the predictions made by any of the three models of social influence tested, because SIT, SIM and OTR predict that minority members have some impact, however slight, upon the 
majority members.

Although these data appear to show that minorities (especially minorities of one) have basically no impact (under some circumstances) on the opinions of the majority group members, such a conclusion is premature. It is possible that the minority members of the groups in the Tindale et al. (1990) study were influential to the extent that they prevented majority members from becoming even more extreme in their final decision. If this were the case, the influence of the minority members would have been analogous to a reign or a weight, holding the majority members back. Unfortunately, the nature of the data in this investigation do not allow us to explore this possibility. In order to measure directly the impact of minority factions, it is critical to compare groups with minority factions to those without such factions. Furthermore, Tindale et al. did not attempt to address whether minority and majority influence differ qualitatively, rather than quantitatively, as proposed in recent theoretical work in this area (see reviews by Levine, 1980; Levine \& Russo, 1987; Maass \& Clark, 1984; Maass, West, \& Cialdini, 1987). Qualitative Differences in Majority and Minority Influence The models of social influence proposed by Latané (1981), Tanford and Penrod (1984), and Mullen (1983) suggest that minority and majority influence differ only quantitatively, and, therefore, are part of the same 
underlying process. In contrast, Moscovici (1980) argued that minority and majority influence are qualitatively different, with the former resulting in private acceptance and eventual internalization of new ideas, and the latter resulting only in public compliance. Furthermore, Moscovici has attributed these differences to the behavioral style of the source, and has identified several characteristics typical of an influential minority source, including autonomy, a lack of rigidity, the use of logical arguments, fairness, and consistency. Moscovici has argued that these traits (presented by the source and/or perceived by the recipient) lead the recipient of a message to process the arguments differently, and that this different type of processing leads to permanent attitude change.

Majority influence, according to Moscovici, is assumed to provoke peripheral cognitive processes, leading only to public compliance (see Chaiken, 1987 or Petty \& Cacioppo, 1981 for a discussion of the differences between central route and peripheral cognitive processing). Tanford and Penrod (1984) noted that the characteristics named by Moscovici are not necessarily specific to minority influence, and considered source consistency a critical parameter for both majority and minority influence.

Moscovici's (1980) notion that minority influence is more likely than majority influence to lead to permanent internalization has led many theorists to explore the two 
influence types in light of a simple, but crucial, experimental manipulation: private versus public expression of attitude change. Maass and clark (1983) conducted two experiments in an attempt to find support for such a dual process model of social influence. The authors employed a methodological and theoretical synthesis of two independently developed theories - one addressing attitude change in general (Petty \& Cacioppo, 1981), and the other specific to minority and majority influence (Moscovici, 1980). Much in line with both Petty \& Cacioppo's elaboration likelihood model of attitude change, and Moscovici's notion of conversion behavior, the authors proposed that the underlying cognitive processes mediating minority influence generate arguments and counterarguments that lead to permanent attitude change. Majority influence, on the other hand, provokes peripheral cognitive processes that lead to public compliance, rather than private acceptance.

In Experiment 1, the authors were primarily interested in the direction in which subjects' attitudes toward a source would shift in public versus private situations. They simultaneously exposed subjects to both majority and minority influence sources. Subjects with moderate attitudes toward gay rights were exposed to a summary of a discussion about gay rights held by five college students at their university. In half of the conditions, four individuals 
(the majority) argued in favor of, and one individual (the minority) argued against, gay rights. In the other half of the conditions, the majority and minority arguments were reversed. All subjects were then asked to respond to four attitude scales regarding gay rights.

In the public compliance condition the subjects were told that they would join the discussion group, and that their response to the attitude scales would be seen by the five students prior to their joining the group. In the private condition, the subjects placed their "anonymous" responses to the attitude scales in a ballot box.

The results indicated that subjects shifted towards the majority position in the public conditions and towards the minority in the private conditions. This difference in shifting is also reported in many other studies attempting to show the power of minority influence (Moscovici \& Lage, 1976; Moscovici \& Personnaz, 1980; Personnaz, 1981). Experiment 2 (Maass \& Clark, 1983) was designed to explore further the dual process model of social influence by examining the arguments and counterarguments generated by subjects in the same experimental conditions utilized in Experiment 1 . It was expected that the results from Experiment 1 would be replicated. The authors also hypothesized that the minority source of influence would stimulate the subjects to generate more arguments and counterarguments than would the majority source of 
influence. Finally, they also predicted that the generated arguments would mediate private acceptance but not public compliance. After reading the discussion summary, each subject was given fifteen minutes to fill six "idea spaces" with arguments and counterarguments for each source of influence.

The shift toward the minority in private, and toward the majority in public was found once again in Experiment 2. However, contrary to the second hypothesis, the minority influence source failed to provoke the generation of more arguments, regardless of direction. The third, and perhaps most critical, hypothesis: that generated arguments would mediate private acceptance but not public compliance, was supported. This finding led the authors to propose that it is not cognitive activity per se, but rather the quality of cognitive activity that accounts for differences in shifting.

In line with this argument, Nemeth (1986) has proposed that minority influence inspires individuals to think divergently, whereas majority influence forces individuals to think convergently. Divergent thinking (Guilford, 1956) is characterized by idea "fluency" (the generation of many ideas) and idea "flexibility" (the generation of ideas from several distinct idea classes or categories), whereas convergent thinking involves the generation of one idea that is representative of the dominant or normative response set. 
The propensity of majority influence to provoke convergent thinking has been explained theoretically in light of the extensive literature on group creativity (Nemeth, 1986). Interacting groups are less likely to generate an idea that is more novel, atypical, or creative than are nominal groups with individuals working alone (McGrath, 1984). This difference is probably the result of the tendency of the individual group members to move toward uniformity, and of each individual group member's fear of being ridiculed for the generation of a "bad" idea.

Nemeth (1986) claimed that an individual facing majority influence will behave in a similar manner (i.e., less likely to generate novel ideas) for the same reasons. Minority influence, on the other hand, inspires the individual to think about novel and creative ideas. It is not clear whether this process is the result of modeling (e.g., individuals see other individuals who think in what appears to be a divergent fashion and choose to do so themselves), or if mere exposure to non-dominant arguments inspires one to think divergently. Nevertheless, Nemeth provides much experimental evidence in support of the notion that minorities are more capable than majorities to inspire divergent thinking (Nemeth \& Kwan, 1985; Nemeth \& Wachtler, 1983).

Perhaps most relevant to the approach taken in this paper is the study by Nemeth and Kwan (1985), in which it 
was shown not only that individuals who are exposed to minority influence think more divergently, but also that this thought style generalizes to subsequent unrelated tasks. Nemeth \& Kwan (1985) first exposed subjects to either majority or minority influence in a color perception task (much like the technique used in earlier Moscovici studies). Following this task, subjects were asked to free associate with the colors green and blue (the colors used in the color perception task). Those who had been exposed to minority influence in the previous task gave more original responses (i.e., statistically infrequent according to a normative list) than those who were exposed to majority influence for both colors. These data also lend support to the notion that majority influence provokes convergent thinking, in that individuals who were exposed to majority influence gave responses that were more conventional than a control group that did not participate in the color perception task.

Majority and minority influence have rarely been studied in the context of freely interacting groups. The reliance on confederates in most studies of social influence may have some very serious effects upon the results obtained in such studies, and these effects may be most critical with respect to minority influence. Assuming that influence is an interactive phenomenon, and that minority members will be influenced by majority members and vice versa, it is 
critical to use true members of each influence type in order to understand fully the impact of both majorities and minorities.

Maass and Clark (1983) did make an attempt to expose subjects to each influence type by using subjects whom they assumed would consider themselves neither a member of the majority nor the minority (they all had moderate attitudes towards gay rights), but their method of accomplishing this should be questioned. The experimenters assumed that subjects with moderate attitudes were neutral with respect to gay rights, a potentially tenuous assumption. Furthermore, a moderate attitude, by their definition, was one that fell within the range of 2.75 and 5.25 on a seven point scale. Given the broad range of what the authors consider moderate, it seems possible that subjects with an "extreme moderate" (e.g., 5.25) pro attitude could consider themselves as members of either the "pro gay rights" minority or majority, rather than as a neutral figure. Perhaps more important, even though subjects were being exposed simultaneously to both influence types, they were reading the arguments from a prepared script and had no opportunity to act as influencing agents themselves, or to experience the feedback from fellow group members. A better method of accomplishing the simultaneous exposure to both influence types would involve using freely interacting groups with both minority and majority members. 
In light of the behavioral characteristics assumed to be critical predictors of the degree to which a minority member will be influential (perhaps with consistency being the most important attribute), one could expect to find different results when all minority and majority members are truly allowed to become influenced and behave accordingly. outline of the Present Study and Research Hypotheses

It was pointed out earlier that the impact of minority factions cannot be completely understood or measured without the use of a control group consisting of no minority faction. By contrasting the two types of group composition (groups with a minority faction and groups with no minority faction), one can draw conclusions with respect to the amount of influence exerted by the minority faction. Such a control group was utilized in the present study. The main purpose of this study was to measure the degree of minority impact on majority members by comparing the post group discussion attitudes for majority members in groups that do versus do not contain a minority faction (i.e., unanimous groups vs. groups with one or two minority members). The possibility that minority influence is qualitatively different in nature was also explored.

It was hypothesized that unanimous groups will, on the average, become more polarized in their final post-discussion attitudes than those with minorities present. Similarly, groups with larger minority factions 
were hypothesized to be, on the average, more moderate than those with only one minority member; that is, minorities of two will be more powerful than minorities of one. This prediction is much in line with previous studies of minority influence (Arbuthnot \& Wayner, 1982; Bray Johnson, \& Chilstrom, 1982; Tindale et al., 1990), and with the three models of social influence discussed earlier (Latané, 1981; Mullen, 1983; Tanford \& Penrod, 1984).

Possible qualitative differences between the two influence types were also explored using a method similar to that used by Maass and Clark (1983). It was hypothesized that majority members in groups with a minority faction would generate more thoughts than those in unanimous groups. It was also hypothesized that the arguments generated by individuals who were members of groups with a minority faction would be more flexible in nature (representative of both sides of the argument).

As mentioned earlier, Nemeth (1986) has concluded that minorities inspire divergent thinking in different conceptual domains. As a direct test of this assertion, the subjects in the present experiment were asked to generate arguments for another social issue that was unrelated to the issue they discussed as a group. Thus, for this particular issue it was expected that majority members of groups with minority factions would generate more ideas as well as ideas that were more flexible in nature, than members who were 
part of unanimous groups. 
METHOD

\section{Subjects}

The subjects were 150 undergraduate students drawn from the Loyola University, Chicago subject pool. The data were collected in single gender groups in an attempt to avoid the possibility of confounding gender and influence type. Subjects participated for approximately one hour and received course credit for their participation. Design

Because the major factor of interest in this study was group composition, five person groups with the following compositions were formed: ten groups of five individuals, in which all members were in favor of the government passing a law that would establish English as the official language of the United States; ten groups of five individuals, in which four members were in favor and one member was opposed to the government passing a law that would establish English as the official language of the United States; and finally, ten groups of five individuals, in which three members were in favor and two members were opposed to the government passing a law that would establish English as the official language of the United States. Thus, a one factor design with three levels was used. Several dependent measures designed to 
investigate the possible qualitative differences between majority and minority influence were collected along with post-discussion attitude scores.

Procedure

Upon arrival, subjects were seated at a large table. They were informed that they would take part in a group discussion, and that the discussion would be audiotaped. First, subjects responded to a pretest comprised of two questions regarding the government passing a law that would establish English as the official language of the United States (see Appendix $A$ ). The first question required the subjects to respond categorically (in favor/against) to the issue of establishing English as the official language of the United states, and the second question required them to respond to a 21-point bipolar scale (ranging from 50 to -50 in intervals of 5 , with a midpoint of zero) indicating the degree to which he/she was in favor/against the issue. The 21-point bipolar scale was used in an attempt to minimize the chances of obtaining ceiling effects. This particular issue was selected based on pilot test data, collected during the Fall semester 1991, that indicated that approximately $85.4 \%$ of undergraduate psychology students were in favor of, and $14.6 \%$ were opposed to the government passing a law that would establish English as the official language of the United States. This distribution allowed for the formation of groups according to the experimental 
design mentioned previously.

After responding to the pretest, subjects in the group conditions were asked to discuss with their fellow group members for approximately seven minutes the issue of our government passing a law that would establish English as the official language of the United States. All discussions were audiotaped in order to keep track of the arguments generated during discussions, and of which source of influence (minority or majority) generated each argument. Group consensus was not required or requested. After group discussion, all subjects were asked to respond to the 100-point scale and to state their position regarding the issue just discussed. All subjects were then instructed to work independently, and to generate a list of thoughts relevant to the issue (see Appendix B). Although the subjects were verbally instructed to generate only a list of relevant thoughts regarding the issue, they were given two sheets of paper divided into two columns (arguments/counterarguments) and told to place each of their thoughts in the appropriate column. Subjects were told that they should not feel as if they had to fill in an equal number of spaces on each side, but rather to list all of the thoughts that came to their mind.

After listing their thoughts, the subjects responded both categorically and to a 21-point bipolar scale (ranging from 50 to -50 in intervals of five with a midpoint of zero) 
regarding the issue of allowing homosexuals to marry legally (see Appendix C). The subjects were then asked to generate thoughts regarding this issue (see Appendix D) using the same format as for the first issue. Upon completion of the final task, subjects were debriefed and thanked for their participation (see Appendix E) . 
Results

In the context of this study, minority and majority influence can be gauged primarily by the direction of the movement of subjects' responses on the 21-point bipolar scale. Theoretically, this movement was predicted to be in the opposite direction for minority and majority influence. A different pattern of results was predicted for the majority and minority members of each group. Therefore, the data obtained from members of minorities and majorities within groups were analyzed separately. The analyses corresponding to the individuals who were majority members in each group may be found under the minority influence subheadings. The analyses corresponding to the individuals who were minority members in each group are presented under the majority influence headings.

Myers, DiCecco, \& Lorch (1981) argue that group level data are often analyzed incorrectly because, in many instances, the individual scores that comprise the group averages are not independently distributed, that is, they are correlated. This tends to inflate the probability of making a Type I error, because the variance attributable to the covariation of individual scores contributes more to the numerator than to the denominator of the test statistic. 
When the individual scores are correlated, and the unit of analysis is the individual, quasi $-\underline{F}$ ratios should be computed in order to ensure that the expected value of the $F$ ratio under the null hypothesis equals one. Therefore, quasi-F ratios were computed where appropriate, as noted, for the analyses reported below.

In order to test the hypotheses corresponding to attitude change, change scores were computed for all individuals. Change scores were calculated by subtracting the posttest attitude score from the prettest attitude score. The means for both the pretest and the posttest attitude scores, for each condition are presented in Table 1 below. 
Table 1

Mean Attitude Scores and Standard Deviations at Pretest and Posttest for Minority and Majority Influence Types

\begin{tabular}{|c|c|c|c|c|c|c|}
\hline \multirow[b]{3}{*}{$\begin{array}{l}\text { Group Member } \\
\text { Type }\end{array}$} & & & \multicolumn{2}{|c|}{ Condition } & & \\
\hline & \multicolumn{2}{|c|}{$\begin{array}{l}\text { Unanimous } \\
\text { Groups }\end{array}$} & \multicolumn{2}{|c|}{$\begin{array}{c}\text { Four Majority } \\
\text { Members }\end{array}$} & \multicolumn{2}{|c|}{ Three Majority } \\
\hline & & & One $\begin{aligned} \mathrm{Mi} \\
\mathrm{Me}\end{aligned}$ & ity & Two $\begin{array}{r}\mathrm{Mi} \\
\mathrm{Me}\end{array}$ & $\begin{array}{l}\text { ority } \\
\text { sers }\end{array}$ \\
\hline & Pre & Post & Pre & Post & Pre & Post \\
\hline Minority & $\star \star \star *$ & $* * *$ & $\begin{array}{r}-25.0 \\
13.5\end{array}$ & $\begin{array}{r}.0 \\
17.8\end{array}$ & $\begin{array}{r}-26.8 \\
13.3\end{array}$ & $\begin{array}{r}-18.8 \\
16.5\end{array}$ \\
\hline Majority & $\begin{array}{l}31.8 \\
13.4\end{array}$ & $\begin{array}{l}36.8 \\
12.2\end{array}$ & $\begin{array}{l}33.1 \\
12.4\end{array}$ & $\begin{array}{l}34.0 \\
17.3\end{array}$ & $\begin{array}{l}32.3 \\
13.5\end{array}$ & $\begin{array}{l}29.2 \\
15.0\end{array}$ \\
\hline
\end{tabular}

Note. The first number corresponds to the mean attitude score, the second number corresponds to the standard deviation.

The mean change score for each influence type, for each condition within the experimental design, is presented in Table 2 below. 
Table 2

Mean Change Scores standard Deviations and Cell size

for Minority and Majority Influence Types

Condition

\begin{tabular}{|c|c|c|c|}
\hline & $\begin{array}{l}\text { Unanimous } \\
\text { Groups }\end{array}$ & $\begin{array}{c}\text { Four Majority } \\
\text { Members }\end{array}$ & Three Majority \\
\hline $\begin{array}{l}\text { Group Member } \\
\text { Type }\end{array}$ & & $\begin{array}{c}\text { One Minority } \\
\text { Member }\end{array}$ & $\begin{array}{c}\text { Two Minority } \\
\text { Members }\end{array}$ \\
\hline
\end{tabular}

Minority

$\begin{array}{lc}25.00 & 8.00 \\ 16.67 & 9.41 \\ (n=10) & (n=20)\end{array}$

Majority

$\begin{array}{cc}5.00 & .88 \\ 5.46 & 7.02 \\ (n=50) & (n=40)\end{array}$

$-3.17$

4.11

$(\mathrm{n}=30)$

Note. Positive change scores indicate movement toward the majority position. Negative change scores indicate movement toward minority position. The first number is the change score mean, the second is the standard deviation, and the third is the number of individuals within the cell.

\section{Attitude Change Due to Minority Influence}

It was hypothesized that individuals in groups with no minority members (unanimous groups) would become more extreme in their post-discussion attitudes than would individuals in groups with one or two minority members present.

A one-way analysis of variance (using the quasi-F procedure described previously) with three levels (unanimous groups, groups with one minority, groups with two

minorities) was performed on the change scores. The analysis of variance source table is presented in Table 3. 
Table 3

Analysis of Variance Source Table for Change Scores

Unanimous Groups and Groups Exposed to Minority Influence

$\begin{array}{cccccc}\text { Source } & \begin{array}{c}\text { Degrees } \\ \text { of }\end{array} & \begin{array}{c}\text { Mean } \\ \text { Square }\end{array} & \begin{array}{c}\text { Quasi } \\ \text { F }\end{array} & \underline{p} & \underline{\omega}^{2}\end{array}$

Freedom

Between

Groups

2

$1,336.03$

$10.42 \quad .01$

.42

Within

Groups

As predicted, a significant main effect for condition was found. Two a priori determined follow up tests were performed. The first compared the unanimous groups condition to a weighted combination of the minority influence conditions. As predicted, the attitude change scores of individuals who were members of unanimous groups differed significantly from those of the individuals in both minority influence conditions $\underline{F}^{\prime}(1,19)=7.00, p<.025$. Unanimous groups became more extreme in their postdiscussion attitudes, whereas groups with one minority member changed very little, and groups with two minority members actually became less extreme (see Table 1 for means). The pattern of means supports the notion that single minority members are influential in a way that prevents the majority members from becoming more extreme. The second follow-up test, contrary to expectations, revealed that there were no significant differences between 
the two minority influence conditions, ${\underline{F^{\prime}}}^{\prime}(1,16)=2.47$, n.s. Possible changes in the dichotomous (In favor/Against) responses were assessed using Fisher's Exact test. The two minority influence conditions were combined for this analysis. The number and relative frequency of individuals who changed their position are presented in Table 4. Table 4

Number and Relative Frequency of Change on Dichotomous Response for Majority Members

Condition

\begin{tabular}{lcc} 
Change & $\begin{array}{c}\text { Unanimous } \\
\text { Groups }\end{array}$ & $\begin{array}{c}\text { Groups with } \\
\text { Minority } \\
\text { Members }\end{array}$ \\
Yes & 0 & 2 \\
No & .00 & .02 \\
& 50 & 68 \\
& .42 & .56 \\
\hline
\end{tabular}

Note. The first number corresponds to the number of individuals who changed/did not change on the dichotomous response and the second number corresponds to the relative frequency.

There was not a significant relationship between condition (unanimous groups and minority influence) and changes in position (In favor/Against) regarding the issue of establishing English as the official language of the United States, (Fisher's Exact, $\underline{p}=.34$ ).

Attitude Change Due to Majority Influence

In order to test the hypothesis that minorities of one would change in the direction of the majority more than 
would minorities of two, a one-way analysis of variance with two levels (one minority member faced with a majority of four and two minority members faced with a majority of three) was performed on the change scores. Once again, quasi-F ratios were used in this analysis because the unit of analysis is the individual. The analysis of variance source table is presented in Table 5.

Table 5

Analysis of Variance Source Table for Change Scores Minorities of one and Minorities of Two

\begin{tabular}{lccccc} 
Source & $\begin{array}{c}\text { Degrees } \\
\text { of } \\
\text { Freedom }\end{array}$ & $\begin{array}{c}\text { Mean } \\
\text { Square }\end{array}$ & $\begin{array}{c}\text { Quasi } \\
\underline{F}\end{array}$ & $\underline{p}$ & $\underline{\omega}^{2}$ \\
\hline $\begin{array}{l}\text { Between } \\
\text { Groups }\end{array}$ & 1 & 2167.20 & 8.89 & .01 & .33 \\
$\begin{array}{l}\text { Within } \\
\text { Groups }\end{array}$ & 14 & 243.75 & & &
\end{tabular}

As predicted, a significant main effect for condition was found. Minorities of one clearly changed more than did minorities of two (see Table 2 for means). These results are much in line with the predictions made by the three models of social influence (Latané, 1981; Mullen, 1983; and Tanford \& Penrod, 1984).

Possible changes in the dichotomous (In favor/Against) responses were assessed using a Fisher's exact test. The number and relative frequency of individuals who changed their position are presented in Table 6 . 
Table 6

Number and Relative Frequency of Change on Dichotomous Response for Minority Members Condition

\begin{tabular}{cc} 
Groups with & Groups with \\
One Minority & Two Minorities \\
Member & Members \\
\hline
\end{tabular}

Yes

No

Note. The first number corresponds to the number of individuals who changed/did not change on the dichotomous response and the second number corresponds to the relative frequency.

There was not a significant relationship between condition (minority of one, minorities of two) and changes in position (In favor/Against) regarding the issue of establishing English as the official language of the United States, (Fisher's Exact, $\underline{p}=.10)$.

Minority Influence Thought Listing Analyses

The arguments and counterarguments generated by each subject were content analyzed by four independent coders (each set of data was rated by two coders). Each coder determined whether the statements listed represented thoughts in favor of (arguments), against (counterarguments), or irrelevant to the issue, which was either establishing English as the official language of the 
United states or allowing homosexuals to marry legally. The interobserver reliability (percentage agreement) averaged across all coders for the entire data set was approximately 95\%. The number of arguments and counterarguments listed by each individual were used to compute two sets of cognitive activity scores for both issues. Cognitive fluency scores were computed by adding the listed arguments to the listed counterarguments. Cognitive flexibility scores were determined by subtracting counterarguments from arguments and dividing by the cognitive fluency score. The absolute value of this ratio was used in the analyses. Therefore, the cognitive flexibility scores could range from 0 (perfect flexibility, that is, the generation of an equal number of arguments and counterarguments) to 1 (the generation of either arguments or counterarguments only). Minority Influence Cognitive Fluency Analyses: English Language Issue

In order to test the hypothesis that influence type would have an effect upon the number of arguments and counterarguments individuals would generate regarding establishing English as the official language of the United States, a one-way analysis of variance with three levels (unanimous groups, majority members exposed to one minority, and majority members exposed to two minorities) was performed on the cognitive fluency scores for this issue. The analysis of variance source table is presented in Table 
7 below.

Table 7

Analysis of Variance Source Table for Cognitive Fluency Establishing English as the Official Language of U.S. Unanimous Groups and Groups Exposed to Minority Influence

Degrees Mean Quasi $\underline{p} \quad \underline{\omega}^{2}$

Source of Square $\underline{F}$ Freedom

Between

Groups

2

35.43

3.86

.05

.19

Within

Groups

22

9.18

As predicted, a significant main effect for condition was found. An a priori determined follow up test revealed that unanimous groups had lower cognitive fluency scores $(\underline{M}=6.740)$ than majority members exposed to one minority member ( $\underline{M}=7.925)$, and majority members exposed to two minority members $(\underline{M}=7.700), \underline{F}^{\prime}(1,24)=4.47, \underline{p}<.05$ In order to determine whether the differences found between conditions was due to individuals exposed to minority influence generating more counterarguments only, two one-way analyses of variance with three levels were performed on the number of arguments and counterarguments generated for establishing English as the official language of the United states. The analysis of variance source table corresponding to total arguments generated in favor of establishing English as the official language of the United States is 
presented in Table 8.

Table 8

Analysis of Variance Source Table: English Arguments

Unanimous Groups and Groups Exposed to Minority Influence

Source

Degrees of Freedom

Between

Groups

2

17.53

3.62

.05 .16

Within

Groups

$24 \quad 4.84$

A significant main effect for condition was found. A follow up test comparing unanimous groups $(\underline{M}=4.56)$ to a weighted average of the two minority influence conditions, that is groups exposed to a minority of one $(\underline{M}=5.25)$, and groups exposed to two minority members $(\underline{M}=4.87)$, while not statistically significant, showed a trend in the predicted direction $\underline{F}^{\prime}(1,25)=4.08, \underline{p}<.10$. Individuals exposed to minority influence did not generate significantly more arguments than individuals in unanimous groups. The second one-way analysis of variance with three levels was performed on the number of counterarguments generated by the individuals within each condition. The analysis of variance source table for counterarguments generated is presented in Table 9 . 
Table 9

Analysis of Variance Source Table: English Counterarguments Unanimous Groups and Groups Exposed to Minority Influence

$\begin{array}{cllcll}\text { Source } & \begin{array}{c}\text { Degrees } \\ \text { of }\end{array} & \begin{array}{l}\text { Mean } \\ \text { Square }\end{array} & \begin{array}{c}\text { Quasi } \\ \text { f }\end{array} & \underline{p} & \omega^{2}\end{array}$

Between

Groups

2

9.67

2.15

.25

Within

Groups

24

4.48

The mean number of counterarguments generated by unanimous groups $(\underline{M}=2.18)$, groups exposed to one minority $(\underline{M}=2.67)$ and groups exposed to two minority members $(\underline{M}=2.833)$ did not differ significantly.

Minority Influence Cognitive Flexibility Analyses: English Language Issue

In order to test the hypothesis that individuals exposed to minority influence would list thoughts that were more flexible in nature (i.e., were representative of both sides of the issue) a one-way analysis of variance was performed on the individual cognitive fluency scores for establishing English as the official language of the United States. The analysis of variance source table corresponding to the analysis of cognitive fluency scores for the issue of establishing English as the official language of the United States is presented in Table 10. 
Table 10.

Analysis of Variance Source Table: English Flexibility

Unanimous Groups and Groups Exposed to Minority Influence

$\begin{array}{cclccc}\text { Source } & \begin{array}{c}\text { Degrees } \\ \text { of } \\ \text { Freedom }\end{array} & \begin{array}{l}\text { Mean } \\ \text { Square }\end{array} & \text { Quasi } & \text { p } & \underline{\omega}^{2} \\ & & \underline{F} & & \end{array}$

Between

Groups Freedom

within

Groups

2

20
.1887

1.53

.25

.1226

The cognitive flexibility scores for individuals who were members of unanimous groups $(\underline{M}=.3861)$ did not differ significantly from individuals who were exposed to a minority of one $(\underline{M}=.3893)$, or individuals who were exposed to two minority members $(\underline{M}=.2960)$.

Cognitive Fluency Analyses:Homosexuals Legally Marrying Issue

It was hypothesized that individuals who were exposed to minority influence would generate more arguments and counterarguments than would individuals who were members of unanimous groups on a subsequent issue (allowing homosexuals to marry legally), unrelated to the issue discussed as a group. It is important to note at this point that the individual members of the group were not aware of their fellow group members' opinions on this particular issue. An individual was classified as either a minority member or majority member based only on their response to the issue of 
establishing English as the official language of the United States. It was quite feasible that many of the individuals classified as majority members had minority opinions within their respective group regarding this second issue, but the data were collected in such a way that these individuals were never made aware of how their response compared to others. The issue of interest with regard to the following analysis is whether the pattern of results with respect to cognitive activity could be replicated for a subsequent issue not discussed as a group. In order to test this hypothesis, a one-way analysis of variance with three levels (Unanimous groups, minority of one, two minorities) was performed on the cognitive fluency score. Quasi-F ratios were not used for this particular analysis, because there was no group interaction (i.e., discussion, knowledge of one another's position etc.) for this issue.

The analysis of variance source table corresponding to this analysis is presented in Table 11. 
Table 11

Analysis of Variance Source Table: Cognitive Fluency

Allowing Homosexuals to Marry Legally

Unanimous Groups and Groups Exposed to Minority Influence

Source

Degrees Sum of

of Squares Freedom

Between

Groups

2

31.72

15.86

3.08

.05

.04

Within

Groups

117

600.87

5.14

Total

119

632.59

A significant main effect for condition was found. A follow up test comparing unanimous groups $(M=5.60)$ to a weighted average of the two minority influence conditions, that is groups exposed to a minority of one $(\underline{M}=6.75)$, and groups exposed to two minority members $(\underline{M}=6.43)$ revealed that the differences between unanimous and minority influence groups was significant $\underline{F}(1,117)=5.63$, $\underline{p}<.05$. In order to determine whether there were differences between conditions with respect to the type of thoughts generated (arguments/counterarguments), two one-way analyses of variance with three levels were performed on the number of arguments and counterarguments generated for allowing homosexuals to marry legally. It should be noted that arguments/counterarguments were reverse scored for individuals who expressed that they were against allowing 
homosexuals to marry legally. In other words, individuals against allowing homosexuals to marry legally would have placed thoughts in line with their opinion in the counterarguments column and the thoughts against their position in the arguments column. The analysis of variance corresponding to arguments generated is presented in Table 12.

Table 12

Analysis of Variance Source Table: Arguments

Allowing Homosexuals to Marry Legally

Unanimous Groups and Groups Exposed to Minority Influence Source

\section{Degrees}

of Freedom
Within

Groups

Total

\section{Between \\ Between
Groups}

2

Sum of Squares

(2)

\section{Mean}

Square
F

은 $\underline{\omega}^{2}$

\section{Iotal}

117

119

.42

.14

.87

2.95 
Table 13

Analysis of Variance Source Table: Counterarguments

Allowing Homosexuals to Marry Legally

Unanimous Groups and Groups Exposed to Minority Influence Source

Degrees Freedom

Between

Groups

2

23.50

117

332.49

2.84

Within

Groups

119

Total

$$
355.99
$$

Mean Square
$\underline{\mathbf{F}}$

p $\quad \underline{\omega}^{2}$ Squares

(1)

This analysis revealed a significant main effect for condition. A follow up test compared the mean number of counterarguments generated by individuals who were members of unanimous groups $(\underline{M}=1.64)$ to a weighted average of the mean number of counterarguments generated by individuals who were faced with one minority member $(\underline{M}=2.60)$, and individuals who were faced with two minority members $(\underline{M}=2.43)$. This analysis revealed that individuals who were exposed to minority influence generated more counterarguments than individuals who were members of unanimous groups, $\underline{F}(1,117)=7.95, \underline{p}<.01$. Cognitive Flexibility Analyses: Homosexuals Marrying Legally Issue

It was also hypothesized that individuals who were members of groups with minority members would generate 
thoughts that were more flexible in nature than would individuals who were members of unanimous groups for the issue of allowing homosexuals to marry legally. In order to test this hypothesis, a one-way analysis of variance with three levels (individuals in unanimous groups, individuals exposed to one minority member, and individuals exposed to two minority members) was performed on the flexibility scores for the issue of allowing homosexuals to marry legally. The analysis of variance source table for this analysis is presented in Table 14 .

Table 14

Analysis of Variance Source Table: Cognitive Flexibility Allowing Homosexuals to Marry Legally Unanimous Groups and Groups Exposed to Minority Influence Source Degrees Sum of Mean $\quad \underline{F}$ p $\quad \underline{\omega}^{2}$ Freedom

Between

Groups

2
Squares Square

F
$\underline{\omega}^{2}$

Within

Groups

12.917 .11

Total

119

13.019

Contrary to expectations, the cognitive flexibility scores did not differ significantly for individuals who were members of unanimous groups ( $\underline{M}=.4711)$, individuals who were exposed to one minority member $(\underline{M}=.4036)$, and individuals who were exposed to two minority members $(\underline{M}=.4352)$. 


\section{Discussion}

This study was designed to measure directly the impact of minority members upon majority members within the context of freely interacting groups by comparing groups with minority members to those without minority members. More specifically, this study was an attempt to understand better the possible qualitative differences between minority and majority influence.

The mathematical models of social influence reviewed in the introduction of this paper and the empirical test of these models conducted by Tindale et al. (1990) all suggest that minorities of one have relatively little impact upon majorities. It was suggested at the outset of this paper that such a conclusion may be premature because the possibility that minority members reduce the degree of polarization in majority members' attitudes had yet to be explored. The overall pattern of mean change scores obtained in this study offer somewhat tentative empirical support for the notion that minority influence is analogous to a reign or a weight preventing the majority's movement toward a more extreme position. Although the groups that were exposed to a minority of one did shift in the direction of the majority, this shift was very slight (not even one 
point on the 21-point scale), relative to that of the unanimous groups (five points on the 21-point scale).

The prevailing paradigm in the study of social influence has consistently defined influence as movement toward a particular position (i.e., changes in preferences, attitudes etc.). In light of the results obtained in the present study, the dependence upon shifting as evidence that influence has occurred poses a special problem for the study of minority influence. Minority influence (especially in the case of single minorities) may not be strong enough to produce shifts toward the minority position, but this should not necessarily be taken as evidence that no influence has occurred. For example, the results presented in Table 4 revealed that only two of the 40 individuals exposed to minority influence changed their position (In Favor/Against) on the language issue. clearly, the minority members in this study were not influential enough to cause a change in position. On the other hand, the minority members were influential in that they were either able to reduce the degree of polarization in the majority members' attitudes, or cause majority members to shift toward their position. Although it is empirically difficult to measure the type of influence that is being alluded to, the methodology utilized in the present study (a unanimous groups control condition), certainly appears to be promising method of studying minority influence. 
The overall pattern of means for the minority members within each group was in line with the predictions made by the three models of social influence (Latané, 1981; Mullen, 1983; and Tanford \& Penrod, 1984). As the number of minorities increased and the number of majorities decreased, the shifts toward the majority position became less extreme. The results of the present study fail to offer straightforward support for the notion that minority and majority influence differ qualitatively. Although individuals who were members of unanimous groups had significantly lower cognitive fluency scores than the individuals who were exposed to minority influence for the issue of establishing English as the official language of the United states, the pattern of results obtained when arguments and counterarguments were analyzed separately were somewhat counterintuitive. The fact that the three experimental groups differed significantly with respect to the number of arguments generated, but not with respect to the number of counterarguments generated is certainly not in line with the notion that minorities inspire divergent thinking. A divergent thought style for the majority members exposed to minority influence would involve the generation of more counterarguments than the unanimous group members. These results become even more puzzling when one considers that the majority members who were exposed to minority influence were certainly more likely to hear 
arguments against their position than were the individuals who were members of unanimous groups.

The results found are somewhat suggestive of McGuire's (1964) inoculation theory. This theory suggests that when an individual is faced with weak counterarguments against her/his position, these counterarguments prompt the individual to generate more thoughts in line with their own position in an attempt to refute the weak counterarguments. The theory also suggests that these refutational defenses serve to bolster the attitude of the individual. This does not seem to be the case in this particular study because the results obtained for the attitude change scores indicate that the minority members were influential. of course, it cannot be assumed that the arguments and counterarguments generated by the individuals mediated their attitude change because the thoughts were listed after the individuals responded to the post-discussion attitude scale, not before. The differences between the groups with respect to the thought listing data for the second issue (allowing homosexuals to marry legally) suggest that individuals generate more thoughts regarding a subsequent, unrelated issue when they are exposed to minority influence than when they are members of a unanimous group. The interesting difference between the results obtained from the analyses of the two issues is that the results from the second issue are much more in line with what would be expected within the 
divergent thinking paradigm than are the results of the first issue. Individuals exposed to minority influence did not generate significantly more arguments (i.e., thoughts in favor of their own position) than the members of unanimous groups, but they did generate more thoughts against their position. Nemeth (1986) has consistently shown, using a variety of dependent variables, that individuals exposed to minority influence not only think more divergently, but that this thought style generalizes to subsequent, unrelated tasks. The present study attempted to replicate this finding using a different dependent variable (i.e., thought listing data). The present study successfully replicated the finding for the second issue, but failed to do so for the first issue. It is difficult to attribute the pattern of results to any one factor, for the thought listing data for the two issues are not entirely equivalent. That is, the first issue was discussed as a group and the thoughts generated were more than likely affected by the group discussion, whereas the thoughts listed for the second issue were the product of an individual effort. Once again, McGuire's (1964) inoculation theory may be useful in explaining these differences. For the first issue, individuals had to actively participate in a conversation regarding the issue, and because they actually heard the counterarguments generated by the minority members, they may have focused primarily upon generating refutational 
defenses. There was no need to defend one's position for the second issue, therefore, it was not necessary for the individual to direct his/her cognitive activity toward defending his/her position. The absence of motivation to defend their own position may have allowed individuals to think more divergently about the issue.

The differences found in cognitive activity for each issue also point out the importance of studying majority and minority influence in freely interacting groups. It is quite possible that group interaction or the expectation that one will have to interact with group members who have differing opinions leads to a different type of cognitive activity. The studies supporting the notion that minority and majority influence differ qualitatively (e.g., Maass, \& Clark, 1984; Nemeth \& Kwan, 1985; Nemeth \& Wachtler, 1983), have failed to consider this important difference because, in most cases, interaction with other group members was impossible (e.g., reading a prepared script of minority arguments). It was mentioned at the outset of this paper that a different pattern of results might be obtained when minority and majority members actually interact. This hypothesized difference was attributed to the interactive nature of social influence (i.e., minority members influencing and becoming influenced by majority members and vice versa). Although the results of this study reveal differences with respect to cognitive activity when the 
groups interacted and when they did not, the data do not allow for the identification of exactly what brought about this change. It is quite possible that the subjects began to generate arguments in favor of their position as soon as they realized that they would have to discuss the issue. It is also possible that the difference in cognitive activity was brought about after being exposed to the minority arguments. The former explanation has been supported recently by Levine (1991), where individuals who expected to interact with minority or majority members generated more arguments consistent with their own position than individuals who did not expect to interact with others. Nonetheless, more research directed toward this issue certainly needs to be conducted.

The differences in cognitive activity found with respect to the two issues could also be attributed to something inherent in the issue of allowing homosexuals to marry legally. The arguments and counterarguments generated for this particular issue seemed qualitatively different from those generated for establishing English as the official language of the United States. The individuals' position with respect to the issue seemed more apparent when reading over their listed thoughts. This difference, of course, has important implications for the coding of the arguments and counterarguments. If the coders felt as if they could successfully guess the position of the 
individual, this perceived knowledge could have biased their counting of the arguments and counterarguments. Although the intraobserver reliability was quite high (95\%), each of the coders could have been affected in the same manner. Such an outcome would not have altered their overall agreement rate.

The thoughts generated for the issue of establishing English as the official language of the United States seemed to be based more on facts and on the hypothetical implications of establishing such a law, whereas the thoughts generated for the issue of allowing homosexuals to marry legally seemed to be more subjective and affect laden (e.g., being sickened at the thought of homosexuals, considering homosexuals not worthy of their civil rights). It may be that it is more difficult for individuals to generate arguments against their position when the issue lends itself to the generation of facts rather than feelings. That is, one would have to have adequate knowledge of or be quite familiar with the implications of establishing English as the official language of the United States in order to generate a list of arguments and counterarguments regarding the issue. The differences found between the two issues may be due, in part, to different levels of familiarity with the implications of allowing homosexuals to marry legally and establishing English as the official language of the United States. 
It is important to note, at this point, that the thought listing data collected in this study may not reflect completely all of the thoughts the individuals were thinking at the time, and the results obtained in this study should certainly be interpreted in light of this flaw. Although all individuals were given ten minutes to list all of the thoughts they had for both issues, most individuals did not write for the entire ten minutes. Furthermore, even though subjects were instructed to work independently on each task, the experimenter noticed that once it became obvious that one individual in the group had stopped writing, it was only a matter of moments before the other four individuals did the same. If individuals started listing the thoughts in favor of their position and moved to the counterarguments column after the arguments column, (or vice versa for the second issue when the individual was against allowing homosexuals to marry legally) the pattern of results obtained are as would be expected given for the first issue, given that the individuals may have discontinued writing not because they had listed all of their thoughts against the issue, but rather because it appeared as if other members of the group had stopped writing. This flaw could have been avoided had the individuals been moved from the large table and seated in such a way that would make the monitoring of others writing behavior impossible. Although this flaw may help explain the failure to find significant differences 
between groups with respect to the number of counterarguments generated for the first issue, it is not clear why the obtained results for the second issue reveal a significant difference with respect to the number of counterarguments generated.

The mean flexibility scores for both establishing English as the official language and allowing homosexuals to marry legally fail to support the notion that the cognitive activity of individuals who are exposed to minority influence is more flexible in nature. Although the results of one study certainly should not be overgeneralized, and these results should be interpreted in light of the previously mentioned flaw in the collection of the thought listing data, it may be beneficial to investigate alternative measures of divergent thinking. For example, the novelty of the arguments and counterarguments for a particular issue could be explored.

It should be noted that the individuals who coded the arguments and counterarguments were instructed to consider all thoughts in favor of and against the issue regardless of the degree to which they were grounded in reality. That is, fallacious arguments (e.g., "Columbus discovered America and he spoke English, therefore the official language of the United States should be English"; "allowing homosexuals to marry legally would increase the spread of AIDS"; "allowing homosexuals to marry would increase the incidence of 
homosexuality") were considered to be just as valid as thoughts that were more in line with reality. In addition, arguments and counterarguments that were similar in implication but applied to different domains (e.g., "establishing English as the official language of the United States would reduce the amount of money spent on bilingual street signs"; "establishing English as the official language of the United states would reduce the amount of money spent teaching immigrants and their children to speak the language") were considered to be separate thoughts, even though they are representative of the general argument, establishing English as the official language of the United States would reduce the amount of money this country spends accommodating non-English speakers. Perhaps flexibility should not be measured in terms of the quantity, but rather in terms of the quality of arguments/counterarguments generated.

The present study attempted to establish a higher level of ecological validity than is typically found in minority and majority influence studies in that each influence type was investigated within the context of freely interacting groups without the use of confederates. It was suggested that a different pattern of results than is typically found might be obtained because minority and majority members were truly allowed to become influenced and behave accordingly. The fact that the results from this study did not deviate to 
any great extent from the results obtained in past research (with the exception of the cognitive activity results), certainly should not minimize the importance of studying influence within the context of freely interacting groups. 


\section{References}

Arbuthnot, J., \& Wayner, M. (1982). Minority influence:

Effects of size, conversion and sex. Journal of

Psychology, 111, 285-295.

Asch, S. E. (1951). Effects of group pressure upon the modification and distortion of judgments. In H. Geutzkow (Ed.), Groups, leadership and men. Pittsburgh PA:

Carnegie Press.

Asch, S. E. (1952). Social psychology. Englewood Cliffs,

NJ: Prentice Hall.

Asch, S. E. (1956). Studies of independence and conformity:

A minority of one against a unanimous majority.

Psychological Monographs, 70 .

Bray, R. M., Johnson, D., \& Chilstrom, J. (1982). Social

influence by group members with minority opinions: A

comparison of Hollander and Moscovici. Journal of

Personality and Social Psychology, 43, 78-88.

Carver C. S., \& Scheier, M. F. (1981). Attention and selfregulation: A control theory approach to human behavior.

New York: Springer-Verlag.

Chaiken, S. (1987). The heuristic model of persuasion. In M. Zanna, J. Olson, \& C. P. Herman (Eds.), Social influence: 
The Ontario symposium (Vol.5, pp.3-39). Hillsdale, NJ: Lawrence Erlbaum.

Gerard, H. B., Wilhelmy, R. A., \& Connelly, E. S. (1968). Conformity and group size. Journal of Personality and Social Psychology, $\underline{8}, 79-82$.

Guilford, J. P. (1956). The structure of intellect.

Psychological Bulletin, 33, 267-293.

Jackson, J. M. (1986). In defense of social impact theory:

Comment on Mullen. Journal of Personality and Social

Psychology, 50, 511-513.

Jackson, J. M. (1987). Social impact theory: A social forces model of influence. In B. Mullens \& G. Goethals (Eds.) Theories of group behavior. New York: Springer-Verlag. Latané , B., \& Darley, J. M. (1970). The unresponsive bystander: Why doesn't he help? New York: AppletonCentury crofts.

Latané, B., \& Darley, J. M. (1975). Help in a crisis: Bystander responses to an emergency. Morristown, NJ: General Learning Press. Latané, B. (1981). The psychology of social impact. American Psychologist, 36, 343-356. Levine, J. M. (1980). Reaction to opinion deviance in small groups. In P. Paulus (Ed.), Psychology of group influence. (pp. 187-231). Hillsdale, NJ: Erlbaum. Levine, J. M. (1991). Anticipating responses to group discussion: The impact of faction size. Paper presented 
at the Fourteenth Interdisciplinary Conference on Groups, Networks, and Organizations.

Levine, J. M., \& Russo, E. M. (1987). Majority and minority influence. In C. Hendrick (Ed.), Group processes. (pp 13-54). Newbury Park, CA: Sage Publications. Maass, A., \& Clark, R. D., III. (1983). Internalization versus compliance: Differential processes underlying minority influence and conformity. European Journal of Social Psychology, 13, 197-215.

Maass, A., \& Clark, R. D., III. (1984). Hidden impact of minorities:Fifteen years of minority influence research. Psychological Bulletin, 95, 428-450.

Maass, A., West, S. G., \& Cialdini, R. B. (1987) Minority influence and conversion. In C. Hendrick (Ed.), Group processes. (pp. 55-79). Newbury Park, CA: Sage Publications.

McGrath, J. (1984) . Groups: Interaction and performance. Englewood Cliffs, NJ: Prentice Hall. McGuire, W. J. (1964). Inducing resistance to persuasion: Some contemporary approaches. In L. Berkowitz (Ed.), Advances in Experimental Social Psychology, Vol. 1, New York: Academic Press. Moscovici, S., \& Lage, E. (1976). Studies in social influence III: Majority versus minority influence in a group. European Journal of Social Psychology, 6 , 149-174. Moscovici, S. (1980). Toward a theory of conversion 
behavior. In L. Berkowitz (Ed.) Advances in experimental social psychology, (Vol.13, pp. 209-239). New York: Academic Press.

Moscovici, S., \& Personnaz, B. (1980). Studies in social influence $\mathrm{V}$ : Minority influence and conversion behavior in a perceptual task. Journal of Experimental Social Psychology, 16, 270-282.

Mullen, B. (1983). Operationalizing the effect of the group on the individual: $\AA$ self-attention perspective. Journal of Experimental Social Psychology, 19, 295-322.

Mullen, B. (1985). Strength and immediacy of sources: A meta-analytic evaluation of the forgotten elements of social impact theory. Journal of Personality and Social Psychology, 49, 1458-1466.

Myers, J. L. , DiCecco, J. V. \& Lorch, R. F. (1981) . Group dynamics and individual performances: Psuedogroup and quasi-F analyses. Journal of Personality and Social Psychology, 40, 86-98.

Nemeth, C. J. (1986). Differential contributions of majority and minority influence. Psychological Review, 93, 23-32. Nemeth, C., \& Kwan, J. (1985). Originality of word associations as a function of majority vs. minority influence. Social Psychology Ouarterly, 48, 277-282. Nemeth, C., \& Wachtler, J. (1983). Creative problem solving as a result of majority vs. minority influence. European Journal of Social Psychology, 13, 45-55. 
Personnaz, B. (1981). Study in social influence using the spectrometer method: Dynamics of the phenomena of conversion and the covertness in perceptual responses. European Journal of Social Psychology, 11, 431-438.

Petty, R., \& Cacioppo, J. (1986). The elaboration likelihood model of persuasion. In L. Berkowitz (Ed.), Advances in experimental social psychology (Vol.19, pp. 123-205). New York: Academic Press.

Tanford, S., \& Penrod, S. (1984). Social influence model: A formal integration of research on majority and minority influence processes. Psychological Bulletin, 95, $189-225$.

Tindale, R. S., Davis, J. H., Vollrath, D. A., Nagao, D. H., \& Hinsz V. B. (1990). Asymmetrical social influence in freely interacting groups: A test of three models. Journal of Personality and Social Psychology, 58, $438-449$. 
APPENDIX A

English Attitude Scale

Code

Seat

Please answer the following two questions.

1. I am In Favor of

Against

our government passing a law that would make

English the official language of the United States.

2. Please circle the number below which best represents your opinion at this time concerning our government passing a law that would make English the official language of the United States

$+50+45+40+35+30+25+20+15+10+5 \quad 0-5-10-15-20-25-30-35-40-45-50$ Extremely Quite Somewhat Somewhat Quite Extremely IN FAVOR AGAINST 


\section{APPENDIX B}

English Thought Listing Form

Code

Seat

In the spaces provided below, please list all of your thoughts about our government passing a law that would make English the official language of the United States. You will notice that there are separate columns for arguments and counterarguments. Place all of your thoughts in favor of passing a law that makes English the official language of the United States in the arguments column. Place all of your thoughts against passing a law that makes English the official language of the United States in the counterarguments column. Please do not feel as if you need to fill in an equal number of spaces on each side. It is very important, though, that you list every argument and counterargument that comes to mind. Please list each thought separately.

ARGUMENTS

1.

2 .

3 .

.

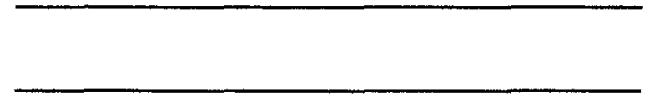

3. 
APPENDIX C

Homosexuals Marrying Attitude Scale

Code

Seat

Please answer the following two questions.

1. I am In Favor of

allowing homosexuals to marry legally.

2.Please circle the number below which best represents your opinion at this time concerning allowing homosexuals to marry legally.

$+50+45+40+35+30+25+20+15+10+5$ o-5-10-15-20-25-30-35-40-45-50 Extremely Quite Somewhat Somewhat Quite Extremely

IN FAVOR

AGAINST 


\section{APPENDIX D \\ Homosexuals Marrying Thought Listing Form}

Code

Seat

In the spaces provided below, please list all of your thoughts about allowing homosexuals to marry legally. You will notice that there are separate columns for arguments and counterarguments. Place all of your thoughts in favor of allowing homosexuals to marry legally in the arguments column. Place all of your thoughts against allowing homosexuals to marry legally int the counterarguments column. Please do not feel as if you need to fill in an equal number of spaces on each side. It is very important, though, that you list every argument ad counterargument that comes to mind. Please list each thought separately.

ARGUMENTS

1 .

2 .

3 .

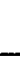

COUNTERARGUMENTS

1 .

2 .

3. 


\section{APPENDIX F \\ Debriefing Form}

Most research regarding minority and majority influence in small groups seems to show that minority members are not as influential as majority members because their numbers are smaller. Most models of social influence predict the same relationship, that is, there is strength in numbers. This study was designed to measure directly the impact of minority members upon the majority members by comparing groups with minority members (individuals who disagree with the majority of their group members) to those without minority members (i.e., unanimous groups). More specifically, this study is an attempt to look at the type of impact minorities have upon majorities, as there is quite a bit of experimental and theoretical work suggesting that there are differences between majority and minority influence.

If you should have any questions regarding this study, please feel free to contact the experimenter, Christine Smith, at 508-3031 or stop by her office in Damen Hall room 661 . Should you care to read more about this particular area of research, the following references would be a great place to start. Thank you very much for your participation.

\section{References}

Maass, A., \& Clark, R.D., III. (1984). Hidden impact of minorities: Fifteen years of influence research. Psychological Bulletin, 95, 428-450. Nemeth, C., \& Kwan, J. (1985). Originality of word associations as a function of majority vs. minority influence. Social Psychology Quarterly, 48, 277-282. Nemeth, C. J. (1986). Differential contributions of majority and minority influence. Psychological Review, 93, 23-32. 


$$
\begin{aligned}
& \text { CURRICULUM VITAE } \\
& \text { Christine M. Smith } \\
& \text { Department of Psychology } \\
& \text { Loyola University, Chicago } \\
& 6525 \text { N. Sheridan Road } \\
& \text { Chicago, IL } 60626
\end{aligned}
$$

\section{Education}

B. A.

1990 Indiana University at South Bend Major: Psychology

Professional Organizations \& Honor Societies

Midwestern Psychological Association, Student Member Psi Chi, National Honor Society in Psychology

\section{Honors and Awards}

Undergraduate research grant, Indiana University at South Bend Award for outstanding Research in Psychology, Indiana University at South Bend

\section{Publications}

Adamopoulos, J., \& Smith, C. M. (in press). The emergence of individualism and collectivism as cultural patterns of interpersonal behavior. In U. Kim, H. C. Triandis, \& G. Yoon (Eds.), Individualism and collectivism: Theoretical and methodological issues. Cambridge, England: Cambridge University Press.

Adamopoulos, J., Smith, C. M., Shilling, C. J., \& Stogiannidou, A. (under review). Cross-cultural invariance in the perception of social environments: A rule-theoretic approach to situational classification. 


\section{Conference Presentations}

Tindale, R. S., Filkins, J., Smith, C., Sheffey, S., \& Thomas, L. S. (1992). Use of probabilistic information by mock civil juries. Poster presented at the Annual Meeting of the Society for Judgement and Decision Making, St. Louis, MO.

Tindale, R. S., Filkins, J., Smith, C., Sheffey, S., \& Thomas, L. S., (1992). Use of "proportional liability" information by mock juries in tort litigation. Paper presented at the Midwestern Psychological Association Annual Convention, Chicago, IL.

Adamopoulos, J., \& Smith, C. M. (1990). The emergence of individualism and collectivism as cultural patterns of interpersonal behavior. Paper presented at "Individualism and Collectivism: Psychocultural Perspectives from East and West", an International Conference sponsored by the Korean Psychological Association, Seoul, Korea.

Smith, C. M., \& Shilling, C. J. (1990). The perception of social environments: Dimensionality obtained with two different tasks. Paper presented at the Midwestern Psychological Association Annual Convention, Chicago, IL. 


\section{APPROVAL SHEET}

The thesis submitted by Christine M. Smith has been read and approved by the following Committee:

Dr. R. Scott Tindale, Director

Associate Professor, Psychology

Loyola University Chicago

Dr. Bernard Dugoni

Assistant Professor, Psychology Loyola University Chicago

The final copies have been examined by the director of the thesis and the signature which appears below verifies the fact that any necessary changes have been incorporated and that the thesis is now given final approval by the committee with reference to content and form.

The thesis is therefore accepted in partial fulfillment of the requirements for the degree of Master of Arts.
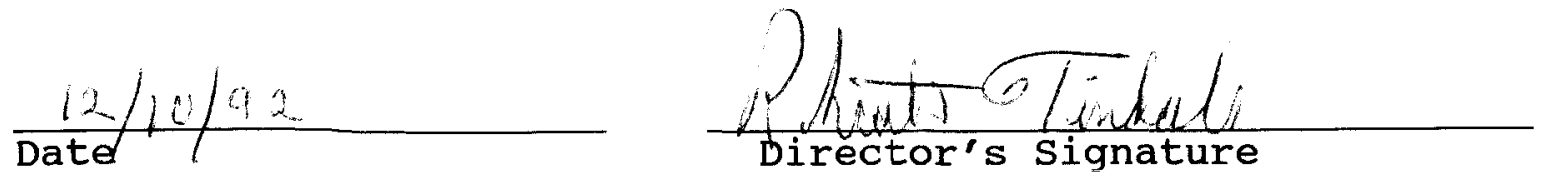